\title{
Christian Müller ist 90 Jahre alt
}

Luc Ciompi

\section{Dank seiner Aufgeschlossenheit für innovative Ver- \\ fahren aller Art entwickelte sich die psychiatrische \\ Universitätsklinik Lausanne unter seiner Leitung bald} zu einem wahren «Mekka der Psychiatrie».

Korrespondenz:

Prof. em. Luc Ciompi

Cita 6

CH-1092 Belmont-sur-Lausanne

cioluci@sunrise.ch
Am 11. August konnte Prof. Dr. med. em. Christian Müller seinen 90. Geburtstag feiern. Müller gilt weit über die Schweiz hinaus als einer der bedeutendsten Pioniere einer psycho- und soziotherapeutisch orientierten Psychiatrie. Sein Werk wie auch seine Person zeichnen sich durch eine ungewöhnliche Vielseitigkeit und Offenheit für Menschen und Ideen aus. Internationales Aufsehen erregte der zuerst in Zürich und dann in Lausanne wirkende Berner, Ehrendoktor der Universität Heidelberg, erstmals in den Fünfzigerjahren des letzten Jahrhunderts: Er publizierte die Heilung eines Falles von schwerer Schizophrenie mit psychoanalytischen Methoden. In der Folge gründete er mit dem Basler Psychotherapeuten Gaetano Benedetti eine internationale Arbeitsgemeinschaft, die heutige International Society for the Psychotherapy of Schizophrenia, die diesen Ansatz in zahlreichen Ländern weiterhin fördert. Dank seiner Aufgeschlossenheit für innovative Verfahren aller Art - darunter die Familientherapie, die therapeutische Nutzung von Film, Musik und Malerei und die gezielte Rehabilitation von Langzeitpatienten -, entwickelte sich die psychiatrische Universitätsklinik Lausanne unter seiner Leitung (von 1962 bis 1986) bald zu einem wahren «Mekka der Psychiatrie», das lernbegierige Ärzte aus aller Welt anzog. Müller war auch einer der ersten Verfechter der systematischen Verkleinerung der früheren psychiatrischen Monsterspitäler zugunsten eines Netzwerkes von kleinen, gemeindezentrierten Übergangsinstitutionen zur Förderung der sozialen Wiedereingliederung. Ausserdem trug er massgeblich zur Schaffung einer ersten Spezialklinik für psychiatrische Alterspatienten im Kanton Waadt bei und initiierte ein umfangreiches, international als «Enquête de Lausanne» bekannt gewordenes Forschungsprogramm zur Untersuchung des Verlaufs psychischer Störungen über mehrere Jahrzehnte, das unter ande-

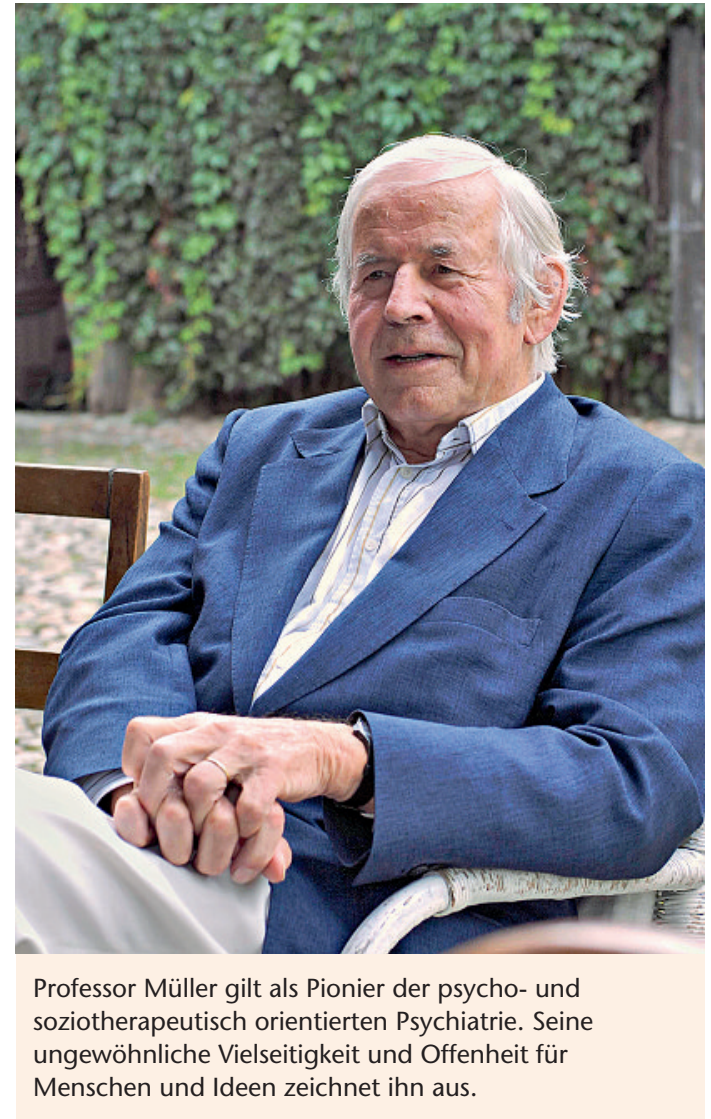

rem neue Erkenntnisse über günstige Alterseinflüsse gerade auch bei gravierenden Störungen mit Einschluss der Schizophrenie erbrachte.

Seit seiner Emeritierung lebt der Jubilar, umgeben von einem weiten Freundeskreis, teilweise in Bern und teilweise in Onnens im Kanton Waadt. Sein umfangreiches wissenschaftliches Werk bereicherte er bis in die letzten Jahre hinein nicht nur mit wichtigen psychiatriehistorischen Studien, so etwa über Paul Dubois und Hermann Rorschach, sondern auch mit einer einzigartigen Sammlung persönlich erlebter Anekdoten, betitelt «Psychiatrische Miniaturen». Noch viel wichtiger als alle Wissenschaft aber ist für alle, die ihn kennen, seine menschliche und persönliche Ausstrahlung, sein Humor und nicht zuletzt die beispielhafte Art, wie er - bei voll erhaltener geistiger Gesundheit - peinigende altersbedingte Schmerzen und Behinderungen mit Würde zu tragen weiss. 